\title{
Incidence of morbidity and associated factors in a Pediatric Intensive Care Unit
}

\author{
Juan P. Álvarez, M.D. ${ }^{a}$, Esteban N. Vázquez, M.D. ${ }^{a}$ and Pablo G. Eulmesekian, M.D. ${ }^{a}$
} ABSTRACT
Introduction. The Functional Status Scale (FSS)
was developed to measure acquired morbidity
in pediatric patients.
Objective. To estimate the incidence of acquired
morbidity in the pediatric intensive care unit
(PICU) and the presence of associated factors, and
describe functional status after hospital discharge.
Population and methods. Prospective cohort.
All PICU admissions between August 2016 and
July 2017 . The FSS was used to measure acquired
morbidity during hospitalization and up to
1 year after discharge. A univariate analysis was
performed to investigate morbidity-associated
factors.

Results. A total of 842 patients were included. The incidence of morbidity at the PICU was $3.56 \%(30 / 842)$ and persisted at $0.7 \%$ for the entire cohort at hospital discharge (6/842). Within 1 year after discharge, the functional status of $3 / 6$ patients improved. The univariate analysis showed an association between acquired morbidity at the PICU and the PIM2 score (odds ratio [OR]: 1.04; $95 \%$ confidence interval [CI]: $1.01-1.07 ; p=0.007)$, age younger than 1 year (OR: $2.93 ; 95 \%$ CI: $1.36-6.15 ; p=0.004)$, the use of assisted mechanical ventilation (AMV) (OR: 7.83; $95 \%$ CI: 3.31-18.49; $p=0.0001$ ) and central venous catheter (CVC) (OR:38.08;95\% CI: 5.16-280.95; $p=0.0001)$, and prolonged hospital stays (OR: 9.65; $95 \%$ CI: 4.33-21.49; $p=0.0001$ ). Conclusions. The incidence of morbidity was $3.56 \%$ and was associated with an age younger than 1 year, patient severity at the time of admission, the use of AMV and CVC, and prolonged hospital stays.

Key words morbidity, functional status scale, pediatrics, intensive care.

a. Department of Pediatric Intensive Care, Hospital Italiano de Buenos Aires, Autonomous City of Buenos Aires, Argentina.

E-mail address: Juan P. Álvarez, M.D.: juan.alvarez@ hospitalitaliano.org.ar

\section{Funding:}

None.

Conflict of interest:

None.

Received: 2-18-2021

Accepted: 5-13-2021 http:/ / dx.doi.org/10.5546/ aap.2021.eng.394

To cite: Álvarez JP, Vázquez EN, Eulmesekian PG. Incidence of morbidity and associated factors in a pediatric intensive care unit. Arch Argent Pediatr 2021;119(6):394-400.

\section{INTRODUCTION}

Mortality in the pediatric intensive care unit (PICU) has decreased, since the beginning of the specialty, from $8-18 \%$ to $3-5 \%$ reported nowadays. ${ }^{1,2}$ However, if we take into consideration that survivors can experience functional disorders that worsen their health status, mortality may not be the only significant outcome variable at the PICU. ${ }^{1}$

The concept of morbidity usually refers to a deviation from the expected results of health care. In the context of critically-ill pediatric patients, it may be considered as the result of the course of certain disease and of the care provided in the PICU. ${ }^{3}$

The incidence of morbidity may be assessed with indicators, such as the development of multiple organ dysfunction, the need for vasoactive drugs, assisted mechanical ventilation (AMV) requirement, and the incidence of nosocomial infections. ${ }^{3-5}$ However, there is growing recognition that the concept of morbidity is associated with decreases in patients' functional status, which persist after the hospital stay. ${ }^{3}$

In 2009, Pollack et al., developed the Functional Status Scale (FSS) in order to obtain an easy quantitative measure concerning the performance of activities of daily living in criticallyill pediatric patients. A difference of 3 points or greater from baseline to hospital discharge defines the presence of morbidity acquired during hospitalization. ${ }^{6,7}$

In recent years, several published studies have used this tool in order to assess morbidity at the PICU, comparing it with other scales and applying it to different subpopulations of critically-ill pediatric patients..$^{8-13}$ Nevertheless, its use is still rare in our 
region, except for its validation and use in some Brazilian PICUs. ${ }^{8,14}$

The objective of this study was to estimate the incidence of acquired morbidity among pediatric patients at the time of discharge from the PICU of Hospital Italiano de Buenos Aires (HIBA) by using the FSS. The secondary objectives included assessing factors associated with acquired morbidity at PICU discharge and describing the course 1 year after hospital discharge in this subgroup of patients.

\section{METHODS \\ Setting}

The PICU at HIBA is a multidisciplinary, 20-bed, closed unit which is part of a general teaching hospital certified by the Joint Commission International (JCI). Approximately 800-850 patients are admitted every year and care is provided to patients with prevalent conditions, transplants, and cancer, and to patients who have undergone general surgery, cardiovascular surgery, neurosurgery, and solid organ transplantation.

\section{Design, population, and study period}

This was a prospective, cohort study. Data were obtained from a database that was specifically created for the follow-up of all patients admitted to the PICU during a 12-month period between August 2016 and July 2017. The functional status of patients with morbidity acquired during hospitalization was assessed up to 12 months after hospital discharge.

\section{Operationalization of variables}

The following variables were defined:

- Morbidity at PICU discharge: The presence of morbidity at PICU discharge is defined as an FSS variation of 3 points or more from admission to PICU discharge. ${ }^{7}$

- Morbidity at hospital discharge: The presence of morbidity at hospital discharge is defined as an FSS variation of 3 points or more from admission to hospital discharge. ${ }^{7}$

- Balance indicators: The following variables were recorded for all patients included in the study: age and sex; diagnostic category; mortality risk score, Pediatric Index of Mortality 2 (PIM2); length of stay at the PICU; mortality at the PICU; days of AMV; use of central venous catheter (CVC); use of renal replacement therapy; and use of extracorporeal membrane oxygenation (ECMO).

\section{Instrument used to estimate morbidity}

The FSS was used to estimate morbidity. This scale was developed and validated as a tool to measure acquired morbidity in pediatric patients. The FSS assesses 6 domains: mental status, sensory, communication, motor function, feeding, and respiratory. The score of each domain may range from 1 to 5 , where 1 represents the best functional status in each of the domains and 5, the worst functional status. ${ }^{6}$ A difference of 3 points or greater from baseline to hospital discharge defines the presence of a significant change in the FSS. Pollack et al. have proposed the following functional status categories: normal function (67), mild dysfunction (8-9), moderate dysfunction (10-15), severe dysfunction (16-20), and very severe dysfunction (21-30). ${ }^{6,7}$ FSS scores with the different domains assessed are attached in Annex.

\section{Statistical analysis}

Descriptive statistics. The characteristics and distribution of variables were analyzed, and means and standard deviations, medians and interquartile ranges, or proportions were used, as applicable.

Univariate analysis. A univariate analysis was performed to investigate the association between independent variables and the outcome variable of morbidity. Categorical independent variables were expressed as percentages. Continuous independent variables were treated in the same way. Student's t test or the Wilcoxon rank-sum test (Mann-Whitney) were used to compare continuous variables, depending on the observed distribution. The $\chi^{2}$ test or Fisher's test were used to compare categorical variables. The significance level was established at 0.05. The statistical analysis was performed with the Stata $9 \circledR$ software (StataCorp, Texas).

\section{Ethical considerations}

Data management. The information obtained during the study conduct was treated in compliance with the provisions of National Law No. 25326 for Personal Data Protection.

Protocol approval. The research protocol was approved by the Research Protocol Ethics Committee of Hospital Italiano de Buenos Aires (approval no. 5160). Given the nature of the study, which did not entail any risk for patients or the privacy of their information, researchers were exempt from asking for an informed consent. 


\section{RESULTS}

The study was conducted between August $1^{\text {st }}, 2016$ and July 31 $1^{\text {st }}, 2017$. During this period, 842 patients were admitted to the PICU. The characteristics of this population are summarized in Table 1.

The median (25-75) FSS score at PICU admission was 6 (6-8). Figure 1 shows the distribution by functional category at admission for the entire cohort. A score of 6 or 7 was observed in $73.28 \%$ (617/842) of patients at PICU admission, which corresponds to the "good functional status" category.

The presence of a new morbidity at PICU discharge was recorded in $3.56 \%$ of patients
(30/842). Figure 2 shows the categorization of patients with acquired morbidity, based on the FSS scores at baseline, at PICU discharge, and at hospital discharge. Out of the 30 patients with acquired morbidity at PICU discharge, $24(80 \%)$ recovered functional status before hospital discharge. Figure 3 shows the FSS domains that were most affected in this group of patients. Although the most affected domain in all patients was feeding (27/30 patients), this alteration resolved before hospital discharge, with morbidity being maintained at this stage only due to respiratory morbidity. Only $0.7 \%$ of patients (6/842) had morbidity at hospital discharge; all of them were discharged with tracheostomies they did not have at PICU admission and $4 / 6$ were

TABLE 1. Characteristics of the population $(n=842)$

\begin{tabular}{|c|c|c|c|}
\hline Variables & & Summary measure & Value \\
\hline Age & Months & Median (25-75) & $60(17-152)$ \\
\hline Sex & Male & $\mathrm{n}(\%)$ & $463(54.98)$ \\
\hline Reason for PICU admission & $\begin{array}{l}\text { Respiratory } \\
\text { Cardiovascular } \\
\text { Neurological } \\
\text { Hepatological } \\
\text { Renal } \\
\text { Cancer } \\
\text { Neuromuscular } \\
\text { Other }\end{array}$ & $\begin{array}{l}\mathrm{n}(\%) \\
\mathrm{n}(\%) \\
\mathrm{n}(\%) \\
\mathrm{n}(\%) \\
\mathrm{n}(\%) \\
\mathrm{n}(\%) \\
\mathrm{n}(\%) \\
\mathrm{n}(\%)\end{array}$ & $\begin{array}{c}89(10.57) \\
247(29.33) \\
92(10.93) \\
93(11.05) \\
45(5.34) \\
65(7.72) \\
49(5.82) \\
162(19.24)\end{array}$ \\
\hline Post-operative patients & & $\mathrm{n}(\%)$ & $558(66.27)$ \\
\hline Surgery type & $\begin{array}{l}\text { Cardiovascular } \\
\text { Neurosurgery } \\
\text { General } \\
\text { Orthopedic } \\
\text { Plastic } \\
\text { Transplant } \\
\text { Other }\end{array}$ & $\begin{array}{l}\text { n (\%) } \\
\text { n (\%) } \\
\text { n (\%) } \\
\text { n (\%) } \\
\text { n (\%) } \\
\text { n (\%) } \\
\text { n (\%) }\end{array}$ & $\begin{array}{c}124(21.95) \\
42(7.43) \\
199(35.22) \\
69(12.21) \\
2(0.35) \\
24(4.25) \\
105(18.58)\end{array}$ \\
\hline Elective admissions & & $\mathrm{n}(\%)$ & $593(70.43)$ \\
\hline PIM2 & & Median (25-75) & $1.6(0.2-2.6)$ \\
\hline Good functional status at PICU admission (FSS 6-7) & & $\mathrm{n}(\%)$ & $617(73.28)$ \\
\hline Assisted mechanical ventilation & & $\mathrm{n}(\%)$ & $263(31.24)$ \\
\hline Central venous catheter & & $\mathrm{n}(\%)$ & $380(45.13)$ \\
\hline Renal replacement therapy & & $\mathrm{n}(\%)$ & $61(7.24)$ \\
\hline ECMO & & $\mathrm{n}(\%)$ & $14(1.66)$ \\
\hline Length of stay (days) & & Median (25-75) & $3(1-6)$ \\
\hline Days of AMV & & Median (25-75) & $2(1-6)$ \\
\hline Mortality at the PICU & & $\mathrm{n}(\%)$ & $33(3.92)$ \\
\hline Morbidity at the PICU & & $\mathrm{n}(\%)$ & $30(3.56)$ \\
\hline Morbidity at hospital discharge & & $\mathrm{n}(\%)$ & $6(0.7)$ \\
\hline
\end{tabular}

ECMO: extracorporeal membrane oxygenation, PICU: pediatric intensive care unit, FSS: Functional Status Scale, AMV: assisted mechanical ventilation, PIM2: Pediatric Index of Mortality 2. 
FIGURE 1. Distribution of functional status categories at admission to the pediatric intensive care unit $(n=842)$

\section{0}

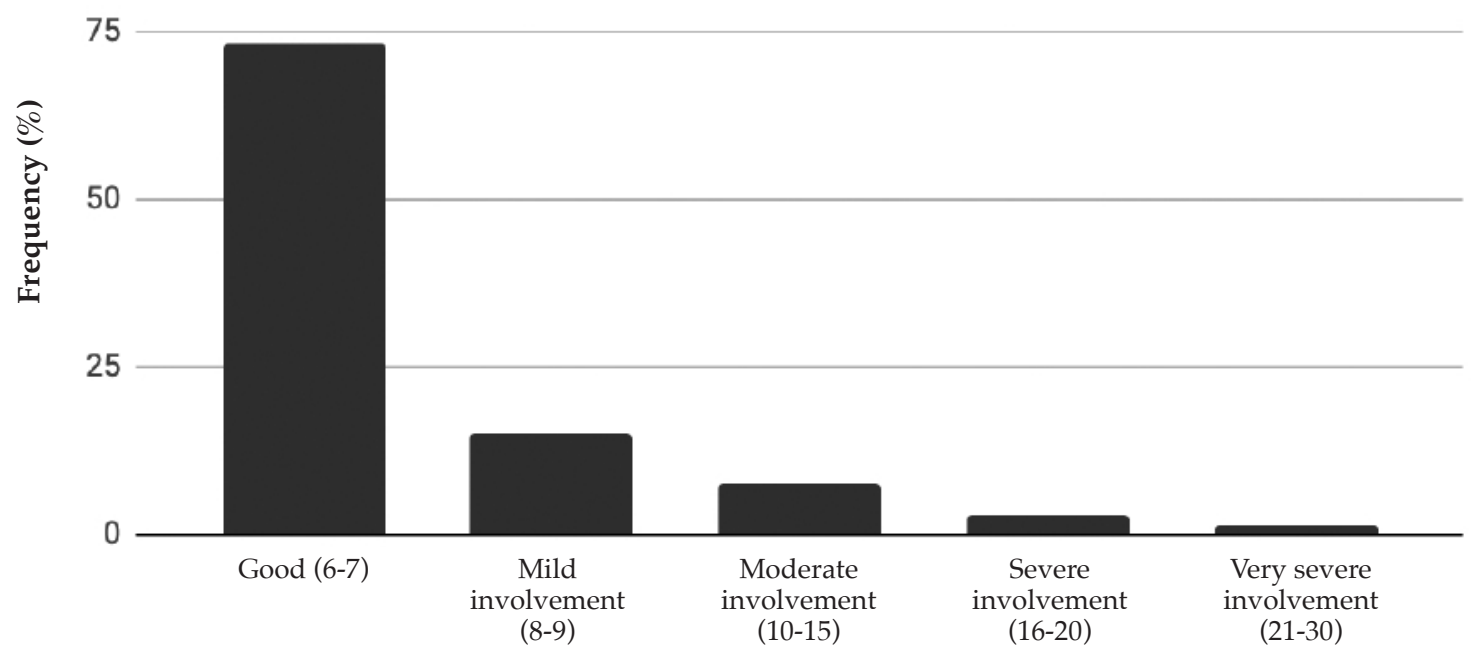

Functional status categories (FSS score)

This figure shows the distribution of patients of the entire cohort, according to the FSS score assigned at PICU admission.

FIGURE 2. Distribution of patients with acquired morbidity at discharge from the pediatric intensive care unit $(n=30)$

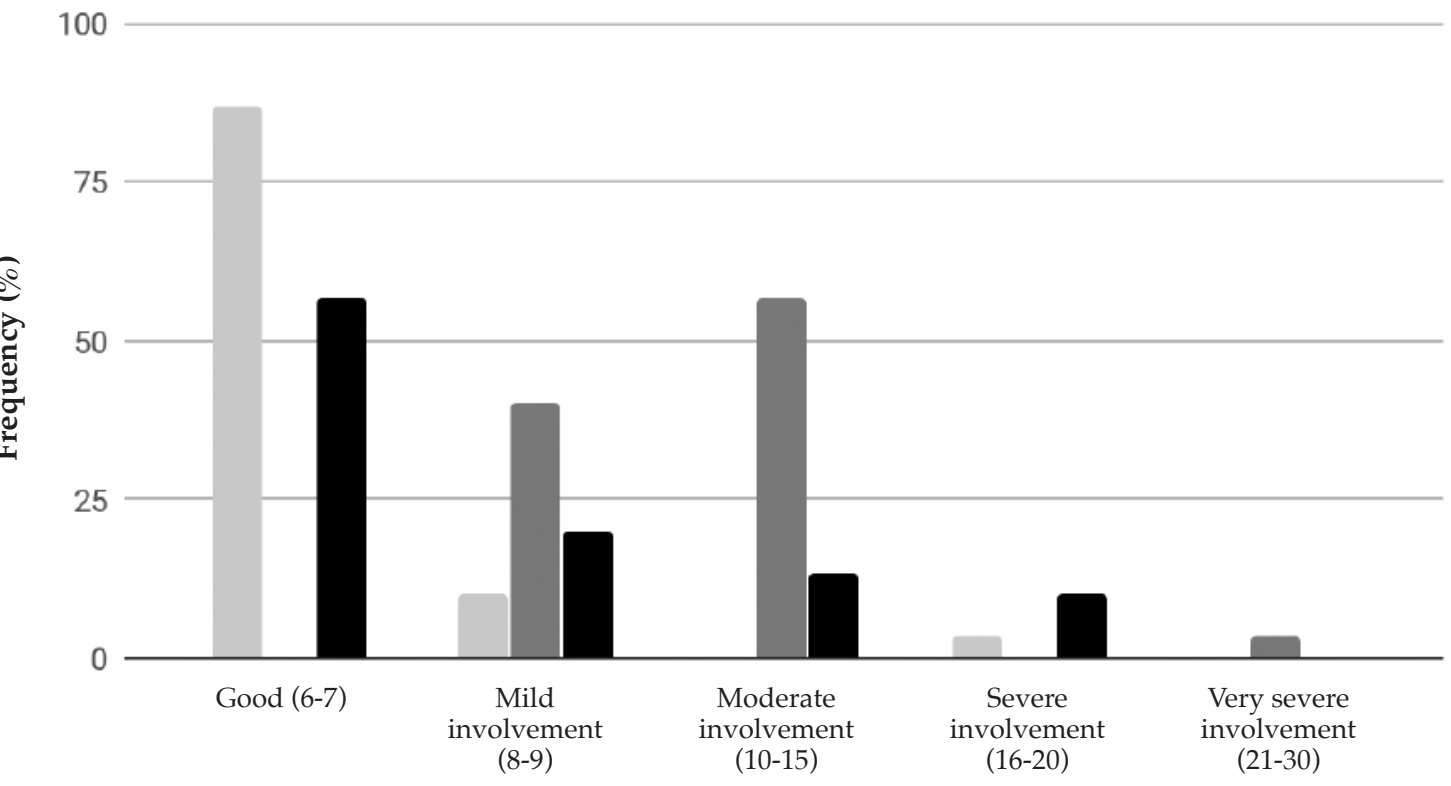

Functional status categories (FSS score)

This figure shows the FSS categories of patients with morbidity at PICU discharge. Light gray, dark gray, and black columns correspond to the FSS categories at admission (baseline score), at PICU discharge, and at hospital discharge, respectively. It is worth noting the change in the frequency $(\%)$ of patients included in each of the 5 categories. Whereas there is a change in the frequency of functional status involvement (acquired morbidity) at PICU discharge (dark gray), this functional involvement improved in a percentage of these patients before hospital discharge (black). 
also on AMV. Among all of them, respiratory functional alteration resolved within 1 year of discharge in $3 / 6$, i.e., AMV, tracheostomy, and oxygen supply were interrupted. Of the remaining 3 patients, 2 continued their treatment in another facility and were lost to follow-up, and 1 still had a tracheostomy without AMV 12 months after hospital discharge.

Table 2 summarizes the univariate analysis. It shows a statistically significant association of the following variables: age younger than 1 year (odds ratio [OR]: 2.93; $95 \%$ confidence interval [CI]: 1.36-6.15; $p=0.004$ ), PIM2 score (OR: 1.04; $95 \%$ CI: 1.01-1.07; $p=0.007$ ), use of AMV (OR: 7.83; $95 \%$ CI: 3.31-18.49; $p=0.0001)$, use of CVC (OR: 38.08; $95 \%$ CI: 5.16-280.95; $p=0.0001$ ), and prolonged hospital stays (OR: 9.65; $95 \%$ CI: 4.3321.49; $p=0.0001$ ) with morbidity at PICU discharge.

\section{DISCUSSION}

The incidence of acquired morbidity at PICU discharge in this cohort, as estimated with the FSS score, was $3.56 \%$, similar to the mortality observed in the same period. Patient severity at PICU admission, age younger than 1 year, the use of CVC and AMV, and prolonged hospital stays were significantly associated with this variable. Out of all patients, only $0.7 \%$ still had a functional alteration at hospital discharge, and most of them were able to recover their functional status within 1 year of hospital discharge.

In 2014, Pollack et al., published the results of the first multicenter cohort of critically-ill pediatric patients and used the FSS to measure morbidity acquired during hospitalization, reporting that the incidence of morbidity doubled mortality $(4.8 \%$ versus $2.4 \%){ }^{7}$ Although these findings are different from the $3.56 \%$ and $0.7 \%$ values observed in our cohort, these authors reported a variability of up to $300 \%$ between the different study sites. ${ }^{7}$

In the univariate analysis, the factors associated with decreases in functional status based on the FSS included age younger than 1 year, mortality risk at PICU admission (PIM2), the use of CVC and AMV, and prolonged hospital stays. Pollack et al. described the association between functional alterations measured with the FSS and age younger than 12 months, and did the same for functional alterations and

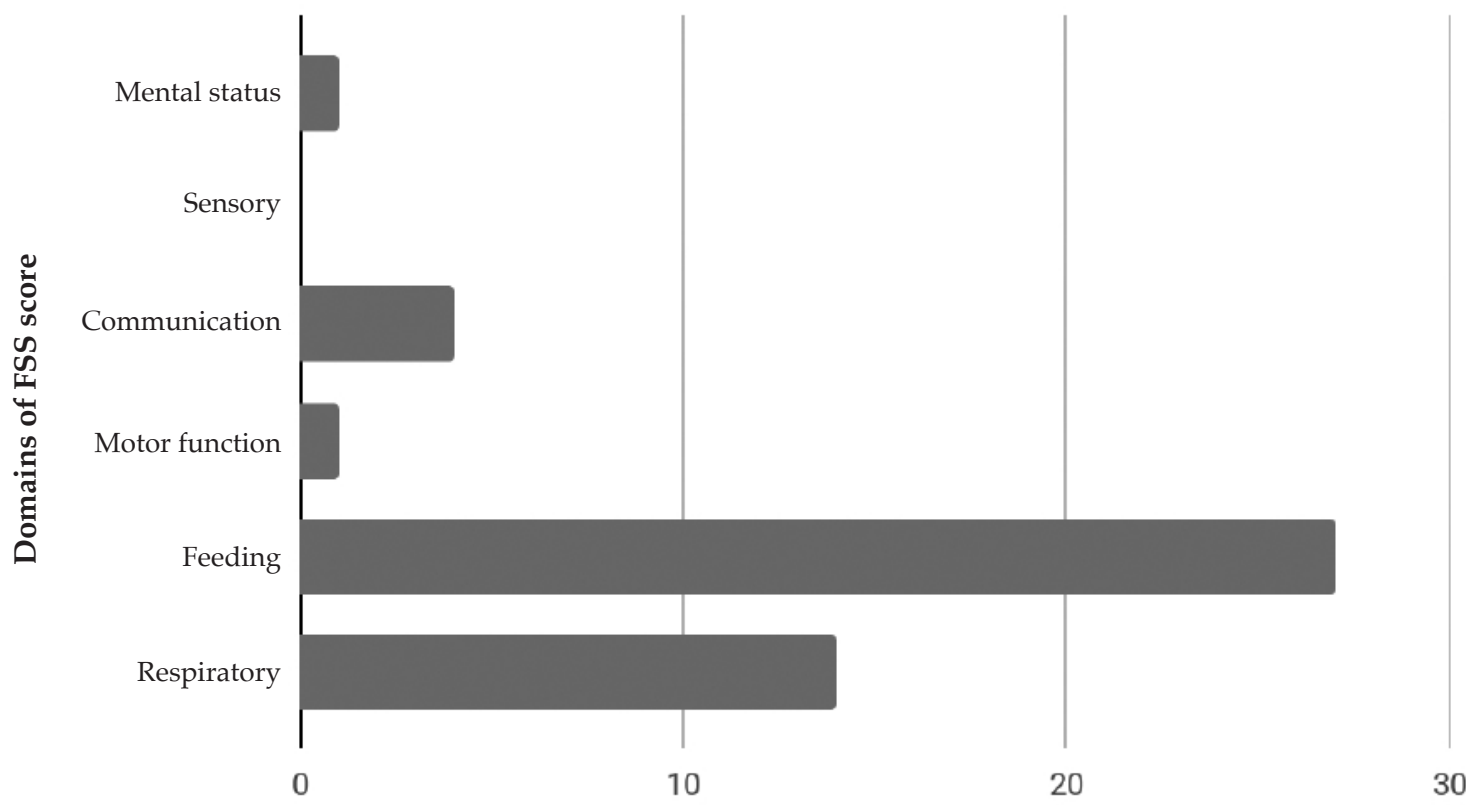

Frequency of FSS score alteration (higher than 1 point) by domain

This figure shows the different domains that contributed with 1 point or more to the presence of acquired morbidity in the pediatric intensive care unit. The feeding domain was the most commonly affected one (27/30), followed by the respiratory domain (14/30). 
physiological alterations at admission (based on the Pediatric Risk of Mortality III [PRISM III] score).${ }^{11}$ Senna et al. also described the association between predictors of severity at admission (using the PIM3 score and the Pediatric Logistic Organ Dysfunction Score 2 [PELOD-2]) and the incidence of acquired morbidity. ${ }^{15}$ Bone et al., did the same using other tools to estimate morbidity: the Pediatric Overall Performance Category (POPC) scale and the Pediatric Cerebral Performance Category (PCPC) scale. ${ }^{16}$

In this cohort, the course of functional status allowed to observe certain decreases in functional status at PICU discharge. The most affected domains were "feeding" and "respiratory." Nevertheless, $80 \%$ of those patients improved their functional status before hospital discharge, and $10 \%$ within one year of discharge; the latter due to the removal of home-AMV and the discontinuation of tracheostomy use. The burden of critical illness not only reflects what happens during the stay at the PICU, but it is also the process resulting from the combination of the disease, the care provided at the PICU, and functional alterations that may persist for months or even years. ${ }^{17}$ Patients who survive critical illness may do so at the expense of physical morbidity (muscle loss and weakness, pain) and non-physical morbidity (depression, anxiety, post-traumatic stress disorder, cognitive impairment). ${ }^{18}$

In recent years, pediatric critical care medicine seems to have extended the assessment of outcomes by complementing mortality with survivors' acquired morbidity. ${ }^{1,3,7,11}$ Assessing patients' functional status at different moments of hospital stay allows to measure the impact of critical illness on this population and target care towards rehabilitation and functional status recovery once the critical phase is over. Although functional alterations persist after the resolution of the initial phase of critical illness, some may be recovered in the following months or even years. ${ }^{19-21}$

This study poses limitations. In first place, its external validity: taking into consideration that this was a single-site study, findings may not be generalized. Another limitation is that associations were obtained by using a univariate analysis. We believe that the shortage of events in relation to associated factors interferes with the development of a robust logistic regression model. Nevertheless, the findings reported by this study may serve as a starting point for the development of multicenter studies that will allow to know the incidence of morbidity in different PICUs from Argentina, in addition to associated factors and the course of said event in the life of critically-ill pediatric patients.

\section{CONCLUSIONS}

The incidence of morbidity at PICU discharge in the study cohort was $3.56 \%$, similar to the mortality observed in the same period. It was associated with age younger than 1 year, patient severity at the time of admission, the use of $\mathrm{AMV}$ and $\mathrm{CVC}$, and prolonged hospital stays. Functional alterations acquired during the PICU stay may change and return to the previous condition, whether during the hospital stay or in long-term outpatient follow-up.

TABLE 2. Univariate analysis

\begin{tabular}{llccc}
\hline Variable & & OR & 95 \% CI & $p$ \\
\hline Infant (age $<$ 1 year) & Categorical & 2.93 & $1.36-6.15$ & 0.004 \\
Post-operative patients & Categorical & 0.87 & $0.41-1.86$ & 0.729 \\
Unscheduled admission & Categorical & 1.19 & $0.55-2.59$ & 0.646 \\
PIM2 (mortality risk) & Continuous & 1.04 & $1.01-1.07$ & 0.007 \\
Mechanical ventilation & Categorical & 7.83 & $3.31-18.49$ & 0.0001 \\
Central venous catheter & Categorical & 38.08 & $5.16-280.95$ & 0.0001 \\
Renal replacement therapy & Categorical & 2.70 & $0.99-7.32$ & 0.051 \\
ECMO & Categorical & 2.11 & $0.26-16.75$ & 0.476 \\
Prolonged hospital stay $(>7 \mathrm{~d})$ & Categorical & 9.65 & $4.33-21.49$ & 0.0001 \\
FSS $>6$ at admission & Categorical & 0.42 & $0.16-1.12$ & 0.084 \\
\hline
\end{tabular}

ECMO: extracorporeal membrane oxygenation, FSS: Functional Status Scale, PIM2: Pediatric Index of Mortality 2, OR: odds ratio, CI: confidence interval. 


\section{REFERENCES}

1. Ong C, Lee JH, Leow MKS, Puthucheary ZA. Functional Outcomes and Physical Impairments in Pediatric Critical Care Survivors: A Scoping Review. Pediatr Crit Care Med. 2016; 17(5):e247-59.

2. Namachivayam P, Shann F, Shekerdemian L, Taylor A, et al. Three decades of pediatric intensive care: Who was admitted, what happened in intensive care, and what happened afterward. Pediatr Crit Care Med. 2010; 11(5):54955.

3. Heneghan JA, Pollack MM. Morbidity: Changing the Outcome Paradigm for Pediatric Critical Care. Pediatr Clin North Am. 2017; 64(5):1147-65.

4. Petros AJ, Marshall JC, van Saene HKF. Should morbidity replace mortality as an endpoint for clinical trials in intensive care? Lancet. 1995; 345(8946):369-71.

5. Jacobs ML, O'Brien SM, Jacobs JP, Mavroudis C, et al. An empirically based tool for analyzing morbidity associated with operations for congenital heart disease. J Thorac Cardiovasc Surg. 2013; 145(4):1046-57.e1.

6. Pollack MM, Holubkov R, Glass P, Dean JM, et al.Functional Status Scale: new pediatric outcome measure. Pediatrics. 2009; 124(1):e18-28.

7. Pollack MM, Holubkov R, Funai T, Clark A, et al. Pediatric intensive care outcomes: development of new morbidities during pediatric critical care. Pediatr Crit Care Med. 2014; 15(9):821-7.

8. Pereira GA, Schaan CW, Ferrari RS. Functional evaluation of pediatric patients after discharge from the intensive care unit using the Functional Status Scale. Rev Bras Ter Intensiva. 2017; 29(4):460-5.

9. Bennett TD, Dixon RR, Kartchner C, DeWitt PE, et al. Functional Status Scale in Children With Traumatic Brain Injury: A Prospective Cohort Study. Pediatr Crit Care Med. 2016; 17(12):1147-56.

10. Cashen K, Reeder R, Dalton HJ, Berg RA, et al. Functional Status of Neonatal and Pediatric Patients After Extracorporeal Membrane Oxygenation. Pediatr Crit Care Med. 2017; 18(6):561-70.

11. Pollack MM, Holubkov R, Funai T, Berger JT, et al. Simultaneous Prediction of New Morbidity, Mortality, and
Survival Without New Morbidity From Pediatric Intensive Care: A New Paradigm for Outcomes Assessment. Crit Care Med. 2015; 43(8):1699-709.

12. Eulmesekian PG, Alvarez JP, Ceriani Cernadas JM, Pérez $\mathrm{A}$, et al. The occurrence of adverse events is associated with increased morbidity and mortality in children admitted to a single pediatric intensive care unit. Eur J Pediatr. 2020; 179(3):473-82.

13. Wolfe HA, Sutton RM, Reeder RW, Meert KL, et al. Functional outcomes among survivors of pediatric inhospital cardiac arrest are associated with baseline neurologic and functional status, but not with diastolic blood pressure during CPR. Resuscitation. 2019; 143:57-65.

14. Bastos VC de S, Carneiro AAL, Barbosa MDSR, Andrade LB de. Brazilian version of the Pediatric Functional Status Scale: translation and cross-cultural adaptation. Rev Bras Ter Intensiva. 2018; 30(3):301-7.

15. Senna S, Ong C, Wong JJ-M, Allen JC Jr, et al. Prediction of Acquired Morbidity Using Illness Severity Indices in Pediatric Intensive Care Patients. Pediatr Crit Care Med. 2020; 21(11):e972-80.

16. Bone MF, Feinglass JM, Goodman DM. Risk factors for acquiring functional and cognitive disabilities during admission to a PICU*. Pediatr Crit Care Med.2014; 15(7):6408.

17. Angus DC, CarletJ, 2002 Brussels Roundtable Participants. Surviving intensive care: a report from the 2002 Brussels Roundtable. Intensive Care Med. 2003; 29(3):368-77.

18. Adhikari NKJ, Fowler RA, Bhagwanjee S, Rubenfeld GD. Critical care and the global burden of critical illness in adults. Lancet. 2010; 376(9749):1339-46.

19. Zinter MS, Holubkov R, Steurer MA, Dvorak CC, et al. Pediatric Hematopoietic Cell Transplant Patients Who Survive Critical Illness Frequently Have Significant but Recoverable Decline in Functional Status. Biol Blood Marrow Transplant. 2018; 24(2):330-6.

20. Typpo KV, Petersen NJ, Petersen LA, Mariscalco MM. Children with chronic illness return to their baseline functional status after organ dysfunction on the first day of admission in the pediatric intensive care unit. J Pediatr. 2010; 157(1):108-13.e1.

21. Pollack MM, Banks R, Holubkov R, Meert KL, et al. LongTerm Outcome of PICU Patients Discharged With New, Functional Status Morbidity. Pediatr Crit Care Med. 2021; 22(1):27-39. 


\section{ANNEX}

FSS score with its different domains

\begin{tabular}{|c|c|c|c|c|c|}
\hline & $\begin{array}{c}1 \\
\text { Normal }\end{array}$ & \begin{tabular}{|c|}
2 \\
Mild dysfunction
\end{tabular} & $\begin{array}{c}3 \\
\text { Moderate } \\
\text { dysfunction }\end{array}$ & $\begin{array}{c}4 \\
\text { Severe } \\
\text { dysfunction }\end{array}$ & $\begin{array}{c}5 \\
\text { Very severe } \\
\text { dysfunction }\end{array}$ \\
\hline Mental status & $\begin{array}{c}\text { Normal } \\
\text { sleep/wake: } \\
\text { appropriate } \\
\text { responsivity }\end{array}$ & $\begin{array}{c}\text { Sleepy but } \\
\text { arousable to } \\
\text { stimulus (noise, } \\
\text { touch, movement) } \\
\text { and/or periods of } \\
\text { non-responsivity } \\
\end{array}$ & $\begin{array}{c}\text { Lethargic and/or } \\
\text { irritable }\end{array}$ & $\begin{array}{l}\text { Minimal arousal } \\
\text { to stimulus } \\
\text { (stupor) }\end{array}$ & $\begin{array}{c}\text { Unresponsive/ } \\
\text { Coma/Vegetative }\end{array}$ \\
\hline Sensory & $\begin{array}{l}\text { Intact hearing and } \\
\text { vision; responsive } \\
\text { to touch }\end{array}$ & $\begin{array}{c}\text { Suspected } \\
\text { hearing or vision } \\
\text { loss }\end{array}$ & $\begin{array}{c}\text { Not reactive to } \\
\text { auditory or visual } \\
\text { stimuli }\end{array}$ & $\begin{array}{l}\text { Not reactive to } \\
\text { auditory and } \\
\text { visual stimuli }\end{array}$ & $\begin{array}{l}\text { Abnormal } \\
\text { response to pain } \\
\text { or touch }\end{array}$ \\
\hline Communication & $\begin{array}{l}\text { Appropriate } \\
\text { (non-crying) } \\
\text { vocalizations; } \\
\text { normal facial } \\
\text { expressiveness } \\
\text { or gestures } \\
\text { (interaction) }\end{array}$ & $\begin{array}{c}\text { Diminished } \\
\text { vocalization, or } \\
\text { diminished facial } \\
\text { expression } \\
\text { and/or social } \\
\text { responsiveness }\end{array}$ & $\begin{array}{l}\text { Absence of } \\
\text { attention }\end{array}$ & $\begin{array}{c}\text { No } \\
\text { demonstration } \\
\text { of discomfort }\end{array}$ & $\begin{array}{c}\text { Absence of } \\
\text { communication }\end{array}$ \\
\hline Motor function & $\begin{array}{c}\text { Coordinated body } \\
\text { movements, } \\
\text { normal muscle } \\
\text { control, and } \\
\text { awareness of } \\
\text { action } \\
\end{array}$ & $\begin{array}{l}\text { One limb } \\
\text { functionally } \\
\text { impaired }\end{array}$ & $\begin{array}{c}\text { Two or more } \\
\text { limbs functionally } \\
\text { impaired }\end{array}$ & Poor head control & $\begin{array}{c}\text { Diffuse spasticity, } \\
\text { paralysis or } \\
\text { decerebrate/deco } \\
\text { rticate posturing }\end{array}$ \\
\hline Feeding & $\begin{array}{l}\text { All food taken by } \\
\text { mouth with age- } \\
\text { appropriate help }\end{array}$ & $\begin{array}{l}\text { NPO or need for } \\
\text { age-inappropriate } \\
\text { help with feeding }\end{array}$ & $\begin{array}{l}\text { Oral and tube } \\
\text { feedings }\end{array}$ & $\begin{array}{c}\text { Parenteral } \\
\text { nutrition with oral } \\
\text { or tube feedings }\end{array}$ & $\begin{array}{l}\text { All parenteral } \\
\text { nutrition }\end{array}$ \\
\hline Respiratory & $\begin{array}{l}\text { Room air and no } \\
\text { artificial support } \\
\text { or aids }\end{array}$ & $\begin{array}{l}\text { Oxygen and/or } \\
\text { suctioning }\end{array}$ & Tracheostomy & \begin{tabular}{|c|} 
CPAP for all or \\
part of the \\
day and/or \\
mechanical \\
ventilator support \\
for part of the day
\end{tabular} & $\begin{array}{c}\text { Mechanical } \\
\text { ventilatory } \\
\text { support for all of } \\
\text { the day and night }\end{array}$ \\
\hline
\end{tabular}

FSS: Functional Status Scale; NPO: nothing by mouth; CPAP: continuous positive airway pressure. 